$\begin{array}{lcl}\text { REVISTA } & \text { CRIANCAS: } \\ \text { DA } \\ \text { FUNDARTE }\end{array}$

\title{
MEDIAÇÃO, LEITURA E LITERATURA
}

Juan Mata Anaya

DOI: 10.19179/2319-0868.787

ANAYA, Juan Mata. Mediação, leitura e literatura. Revista da FUNDARTE. Montenegro, p.01-21, ano 20, no 42, julho/setembro de 2020.

Disponível em: http://.seer.fundarte.rs.gov.br/index.php/RevistadaFundarte/index> 30 de setembro de 2020 


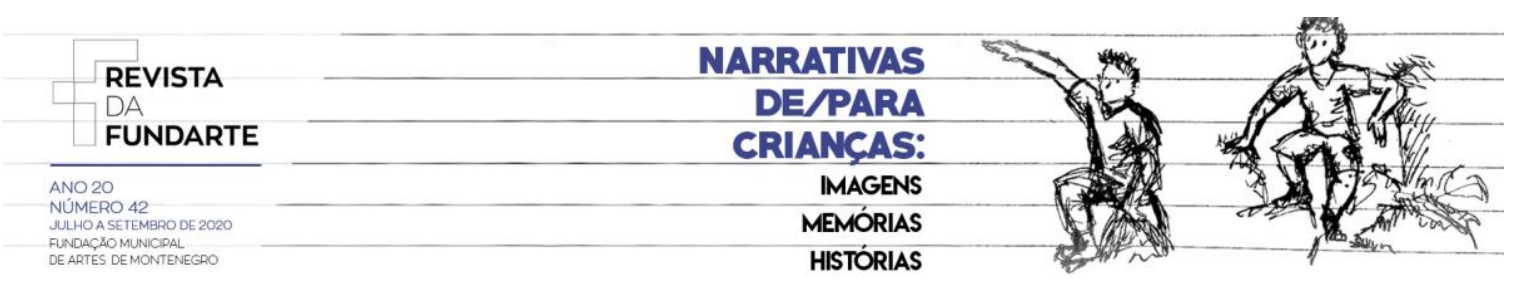

\section{MEDIAÇÃO, LEITURA E LITERATURA}

Juan Mata Anaya ${ }^{1}$

Resumo: O presente artigo busca discutir os processos de mediação de leitura e ampliar a noção da mediação com a literatura. A leitura em voz alta na primeira infância tem o papel de servir de introdução à literatura, principalmente às narrações e à poesia e, além disso, influi decisivamente no desenvolvimento da aprendizagem da leitura (BRYANT y BRADLEY, 1998; CABREJO-PARRA, 2001; WELLS, 1998; WOLF, 2008), por isso essa mediação vai além do mero entretenimento. Por meio de relatos e experiências da Asociación Entrelibros, defendemos a leitura em voz alta de textos literários como um dos mais relevantes modos de mediação, não apenas nos primeiros anos de vida, nos quais logicamente essa mediação é primordial, mas em qualquer etapa e circunstância da vida, pois a voz do outro é um dos mais efetivos meios de aproximação aos textos literários. A mediação literária põe o foco não no patrimônio literário em si, mas nas pessoas e em suas circunstâncias de vida, permite a comunicação e a participação na sociedade letrada, e à palavra poética em particular, que amplia as capacidades individuais de simbolização.

Palavra-chave: Mediação de leitura; Leitura em voz alta; Literatura.

\section{MEDIATIONS, READING AND LITERATURE}

Abstract: This article seeks to discuss the processes of mediation of reading and expand the notion of mediation with literature. Reading aloud in early childhood has the role of serving as an introduction to literature, mainly to narrations and poetry and, moreover, it has a decisive influence on the development of learning to read (BRYANT \& BRADLEY, 1998; CABREJO-PARRA, 2001; WELLS, 1998; WOLF, 2008), so this mediation goes beyond mere entertainment. Through reports and experiences of Asociación Entrelibros, we defend reading aloud literary texts as one of the most relevant modes of mediation, not only in the first years of life, in which logically this mediation is paramount, but in any stage and circumstance of life, because the voice of the other is one of the most effective means of approaching literary texts. Literary mediation focuses not on the literary heritage itself, but on people and their circumstances of life, allows communication and participation in literate society, and the poetic word in particular, which expands the individual capacities of symbolization.

Keywords: Reading mediation; Read aloud; Literature.

\section{MÉDIATION, LECTURE ET LITTÉRATURE}

\footnotetext{
1 Professor aposentado da Facultade de Ciências da Educação da Universidade de Granada (Espanha). Doutor em Didática das Línguas e da Literatura. Publicou diversos livros sobre a mediação literária, tais como "Como mirar a la luna", "Confesiones a una maestra sobre la formación del lector", "El rastro de la voz y otras celebraciones de la lectura". É coordenador da Asociación ENTRELIBROS.
}

ANAYA, Juan Mata. Mediação, leitura e literatura. Revista da FUNDARTE. Montenegro, p.01-21, ano 20, no 42, julho/setembro de 2020.

Disponível em: http://.seer.fundarte.rs.gov.br/index.php/RevistadaFundarte/index> 30 de setembro de 2020 


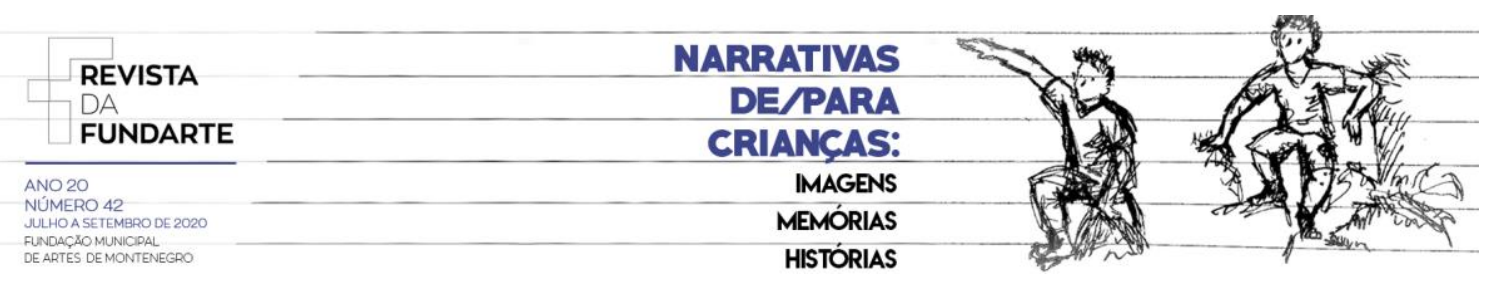

Resumé: Cet article cherche à discuter des processus de médiation de la lecture et à élargir la notion de médiation à la littérature. La lecture à haute voix dans la petite enfance a pour rôle de servir d'introduction à la littérature, principalement aux récits et à la poésie et, en outre, elle a une influence décisive sur le développement de l'apprentissage de la lecture (BRYANT \& BRADLEY, 1998; CABREJO-PARRA, 2001; WELLS, 1998; WOLF, 2008), cette médiation va donc au-delà du simple divertissement. À travers les rapports et les expériences de I'Asociación Entrelibros, nous défendons la lecture des textes littéraires à haute voix comme l'un des modes de médiation les plus pertinents, non seulement dans les premières années de la vie, dans lesquelles cette médiation est logiquement primordiale, mais à n'importe quel stade et circonstance de la vie, car la voix de l'autre est l'un des moyens les plus efficaces d'approcher les textes littéraires. La médiation littéraire ne se concentre pas sur le patrimoine littéraire lui-même, mais sur les personnes et leurs circonstances de vie, permet la communication et la participation à la société alphabétisée, et le mot poétique en particulier, qui élargit les capacités individuelles de symbolisation.

Mots-Clés: Médiation de lecture; Lecture à voix haute; Littérature.

A mediação, em seu sentido mais comum, tem uma longa história. É uma atividade inerente à condição humana e ao desenvolvimento social. Formalizada ou não, a mediação foi e tem sido um dos modos habituais de intervenção quando diferentes interesses entram em conflito e as discrepâncias entram em embate. A mediação sempre tende a evitar que os desacordos se resolvam pelo uso da força, abuso ou agressão física ou moral. Nesses casos, a mediação é sinônimo de negociação, arbitragem ou conciliação. Bonafé-Schmitt (1992) a definiu como a 'justiça doce' e Six (1997) como um "não-poder". A mediação profissional se manifesta em campos tão diversos como o judicial, comercial, laboral, pedagógico, psicanalítico ou cultural.

Não há uma definição unânime acerca do termo mediação. Segue-se usando com diferentes significados e, por conta disso, têm usos muito distintos, às vezes, até divergentes. As definições mais habituais de mediação (GROVER DUFFY, GROSCH; OLCZAK, 1996; MUNNÉ; MAC-CRAGH, 2006; MARQUES CEBOLA, 2013; BLANCO GARCÍA, 2017) ressaltam, por sua vez, a existência prévia de conflitos cuja resolução seja necessária. Vinyamata Camp (2003) a conceitua assim:

Mediação é o processo de comunicação entre as partes em conflito com a ajuda de um mediador imparcial, que procurará que as pessoas envolvidas

ANAYA, Juan Mata. Mediação, leitura e literatura. Revista da FUNDARTE. Montenegro, p.01-21, ano 20, no 42, julho/setembro de 2020.

Disponível em: http://.seer.fundarte.rs.gov.br/index.php/RevistadaFundarte/index> 30 de setembro de 2020 


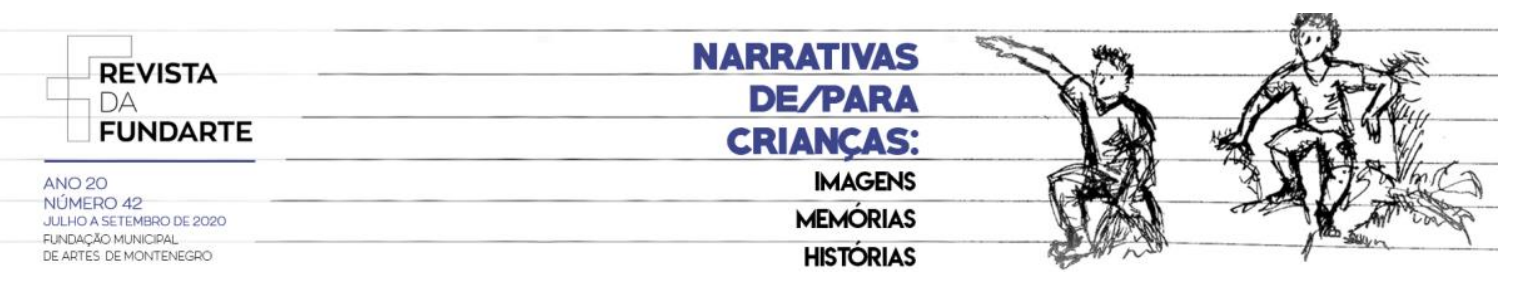

em uma disputa possam estabelecer, por elas mesmas, um acordo que permita restaurar a boa relação e dar por acabado, ou ao menos atenuado, o conflito, que atua preventivamente tendo em vista melhorar as relações com as pessoas. (p. 17)(tradução nossa)

Às vezes não é necessário detectar um conflito para dar início a um processo de mediação, basta pressentir ou prever. A prevenção é um incentivo para mediação. As sociedades contemporâneas, caracterizadas pela diversidade de interesses, pensamentos, costumes, práticas, valores e crenças que convivem, se misturam ou simplesmente compartilham espaços, exigem um esforço contínuo de atenção, organização e harmonização que evite os possíveis conflitos derivados dessa heterogeneidade cultural.

Mediar é também antecipar, promover encontros, criar vínculos. Conforme aumentam os processos migratórios, o conceito de mediação intercultural tem o seu papel acentuado. A mediação intercultural busca estabelecer relações entre tradições e comportamentos muito distintos, facilitar a convivência e a compreensão mútua. Não podemos entendê-la separada de outras mediações sociais, afinal de contas as culturas são construções sociais e, portanto, podem ser objetos de enfrentamento, disputas ou rejeição. A mediação teria neste caso a função de aproximar, unificar, compreender, evitar, aceitar...

Neste sentido, tem-se falado da mediação linguística relacionada ao campo da tradução, que a considera como uma mediação entre línguas (VIAGGIO,2004), assim como uma mediação entre culturas. Os tradutores, mais que 'dicionários ambulantes' seriam na realidade mediadores culturais pois não se limitariam a transpor palavras de uma língua a outra, uma ação que em si mesma faz verter traços culturais ao escolher uma palavra ou outra, já que a linguagem é parte inerente de uma cultura. Atuam com frequência como verdadeiros mediadores interculturais já que intermediam em diversos âmbitos sociais a população local e os recém-chegados.

Nem todas as práticas de mediação se produzem em situações de conflito ou potencialmente conflituosas. A mediação estendeu seu papel para circunstâncias e 


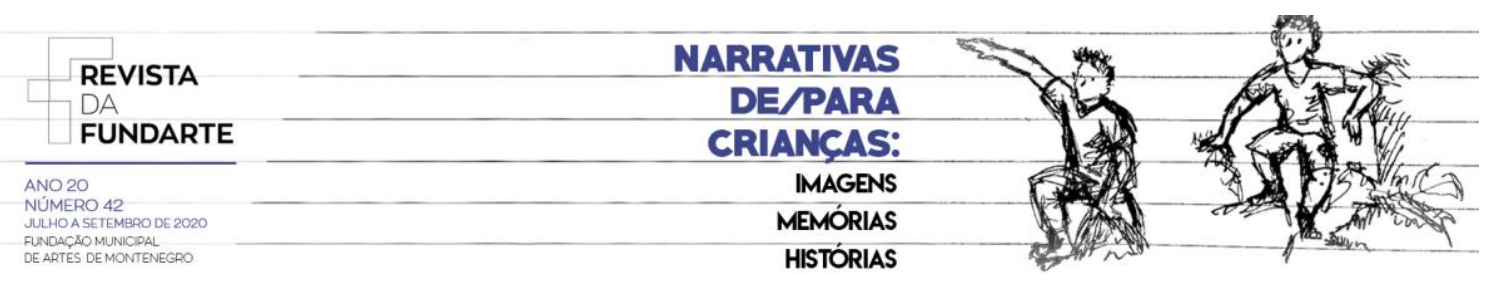

lugares em que não ocorrem enfrentamentos ou conflitos de interesses, mas desconhecimento ou falta de acesso. A mediação seria nesses casos uma forma de descobrir, de criar pontes entre realidades distintas, de tornar interessante e desejável o ignorado. A mediação, neste caso, não buscaria restaurar uma relação deteriorada, mas criar vínculos e afetos.

O aumento da infraestrutura nas áreas culturais, artísticas e científicas na segunda metade do século passado em muitos países ocidentais, consequência do desenvolvimento econômico e social, impulsionou estratégias e práticas que tornaram possível a utilização massiva dos novos espaços culturais. Assim, não bastava construir instalações ou organizar atividades, era necessário torná-las atrativas, convidativas, desejáveis e inteligíveis. Os cidadãos deveriam se apropriar desses espaços, entendê-los como seus. Conceitos como difusão, animação ou mediação adquiriram uma especial relevância. Era preciso divulgar os novos serviços e, ao mesmo tempo, estimular, tornar interessante e abrir canais de comunicação. Assim, iniciou-se uma reflexão sobre protagonismo e os procedimentos do trabalho de animação, acompanhamento e mediação, com o intuito de favorecer a participação dos cidadãos na vida cultural, sobretudo dos excluídos e desfavorecidos. A democratização do saber e o acesso ao patrimônio cultural exigia que se expandisse a base social dos usuários e, por sua vez, dar oportunidade para que esses novos usuários fossem também criadores.

Neste contexto surgiu o conceito de mediação cultural, concebida como um conjunto de práticas com o intuito de facilitar de modo mais efetivo o acesso da população aos serviços e espaços culturais. Essas ações de educação e inclusão social partiam da constatação de que a maioria dos cidadãos dificilmente tinham acesso, hábito e, com frequência, condições para conhecer e desfrutar as obras artísticas, literárias ou científicas de modo que o objetivo prioritário deveria ser garantir o acesso a museus, salas de concerto, teatros e bibliotecas. Para muitas pessoas, os obstáculos econômicos, psicológicos ou geográficos eram - e ainda são 


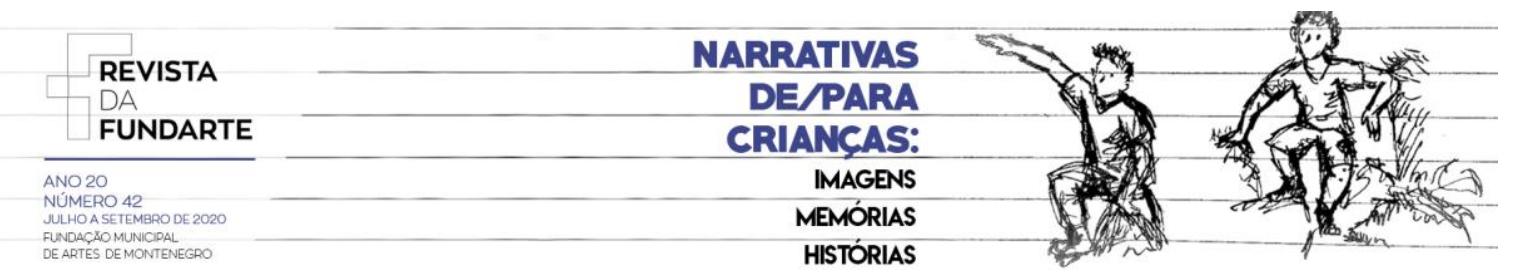

- insuperáveis, de modo que era preciso estabelecer estratégias e práticas que eliminassem essas barreiras. Esse foi o sentido primeiro da mediação cultural.

\section{Mediações e voz}

A mediação no campo da literatura ocorre desde tempos remotos, em todas as culturas, letradas ou não, e entre os mais diversos grupos sociais. A alfabetização universal é uma conquista recente e ainda inacabada, de modo que, durante milhares de anos, o 'normal' era ser ouvinte e não leitor, condição esta minoritária. Quando a literatura era basicamente pela oralidade, os jograis, trovadores, recitadores, cantores, leitores públicos... atuavam no sentido estrito como mediadores literários. Eles se encarregaram de levar, através da voz, as obras literárias às pessoas dos vilarejos e cidades, sendo esses os responsáveis por "publicar" as palavras que inicialmente a poucos pertenciam (MENÉNDEZ PIDAL, 1942; ZUMTHOR, 1989). De um modo ou de outro, também os públicos atuais de teatro, música, contação de histórias, atuam como ouvintes, e os atores, cantores ou narradores, atuam como mediadores. Podemos inclusive dizer que existem práticas que, mesmo no meio letrado, seguem exigindo uma voz mediadora, como é o caso da narração oral de contos populares. Ocorre igualmente com a figura do leitor público que historicamente cumpriu a admirável missão de fazer presente os textos literários na comunidade. Ler em voz alta para os outros foi uma prática habitual em diversos âmbitos sociais, tanto iletrados como amplamente alfabetizados. A leitura em voz alta foi uma prática social na qual participavam pessoas que não sabiam ler ou escrever, mas também membros da burguesia e da nobreza que haviam adquirido essas habilidades. Reunir-se em torno de um livro lido em voz alta era considerada uma atividade de lazer e de relações sociais (CAVALLO; CHARTIER, 1998; MANGUEL, 1998; MATA, 2004). Os próprios autores desde sempre tiveram inclinação para ler suas próprias obras em voz alta diante de diversos públicos chegando, em alguns casos, a considerar-se quase uma prática de caráter 


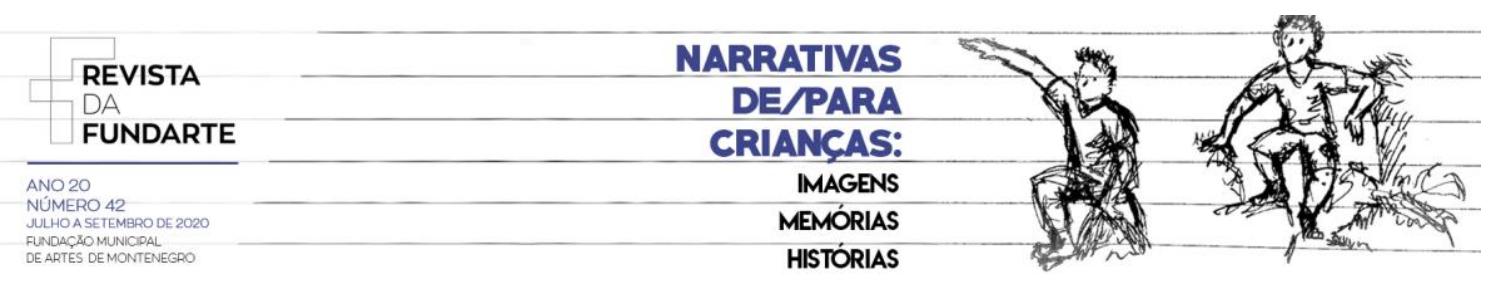

profissional, como foi o caso de Charles Dickens, que enchia salas e teatros com pessoas ávidas por escutar os romances lidos pelo próprio autor.

A leitura em voz alta na primeira infância tem o papel de servir de introdução à literatura, principalmente às narrações e à poesia e, além disso, influi decisivamente no desenvolvimento da aprendizagem da leitura (BRYANT; BRADLEY, 1998; CABREJO-PARRA, 2001; WELLS, 1998; WOLF, 2008), por isso essa mediação vai além do mero entretenimento. Ler em voz alta para as crianças, ou melhor dizendo, com as crianças, tanto em família quanto na escola, é um extraordinário modo de mediação literária. Faz dos livros objetos de conhecimento, fantasia e afeto (BONNAFÉ, 2008). Diversas organizações, em todo o mundo, integradas por profissionais muito diversificados, como pediatras, bibliotecários e professores, ressaltam a relevância dessa mediação precoce. Dentre elas estão Reach Out and Read, Nati per leggere, A.C.C.E.S. (Actions Culturelles Contre les Exclusions Sociales), BookTrust, que defendem a leitura em voz alta desde o momento do nascimento como uma forma progressiva e afetuosa de preparar o cérebro para a aprendizagem posterior da leitura e evitar, deste modo, desigualdades entre os alunos habituados e aos desacostumados com essa prática.

A leitura de textos literários em voz alta segue sendo um dos mais relevantes modos de mediação, não apenas nos primeiros anos de vida, nos quais logicamente essa mediação é primordial, mas em qualquer etapa e circunstância da vida, pois a voz do outro é um dos meios mais efetivos de aproximação aos textos literários. Muitos são os relatos pessoais que destacam a influência determinante dessa atividade na criação de afeto com a leitura. O filósofo Karl Popper (1994) lembra em sua autobiografia esses momentos de deslumbramento com a entrada no mundo da literatura através da voz:

\footnotetext{
O primeiro livro que causou em mim uma grande e duradoura impressão foi lido pela minha mãe para mim e minhas irmãs, pouco antes de eu aprender a ler (eu era o mais novo dos três filhos). Se tratava de um livro para crianças de uma grande escritora sueca chamada Selma Lagerlöf, em uma bela tradução alemã (WunderbareReise des kleinen Nils Holgerssonmit den Wildgänsen; a tradução inglesa leva o título The Wonderful Adventures of
}

ANAYA, Juan Mata. Mediação, leitura e literatura. Revista da FUNDARTE. Montenegro, p.01-21, ano 20, no 42, julho/setembro de 2020.

Disponível em: http://.seer.fundarte.rs.gov.br/index.php/RevistadaFundarte/index> 30 de setembro de 2020 


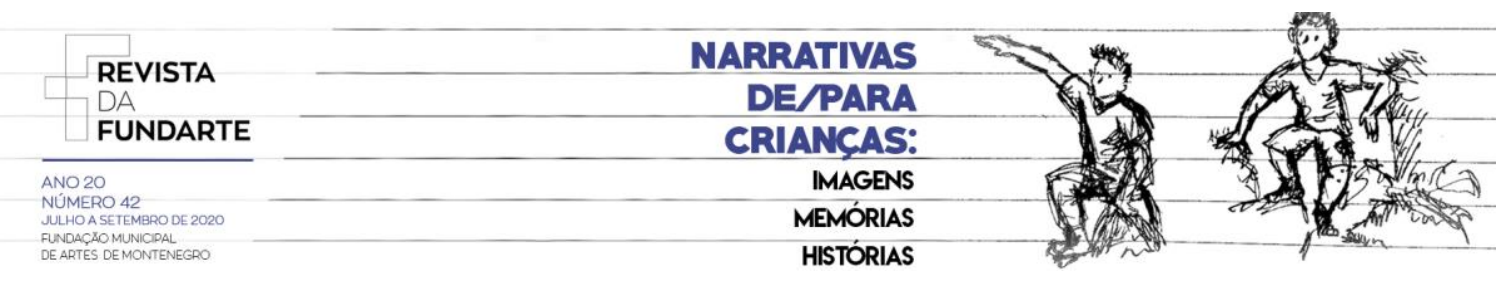

Nils $^{2}$ ). Durante muito, muito tempo eu li esse livro pelo menos uma vez ao ano; e ao longo da minha vida eu li provavelmente toda obra de Selma Lagerlöf mais de uma vez. (p.17)(tradução nossa)

\section{Livros e Mediadores}

Certamente, desde o século $\mathrm{XV}$, com a invenção da imprensa, os impressores podem ser considerados também mediadores, como anteriormente haviam sido os escribas ou os copistas medievais, pois tornam possível que os textos literários cheguem aos potenciais leitores. Assim como eles, todos os que participam do processo de aproximar o público dos textos literários - bibliotecários, livreiros, professores, jornalistas, críticos - podem ser considerados mediadores no sentido amplo. É por isso que parece conveniente pensar no termo 'mediador' mais como adjetivo que como substantivo, uma vez que o uso como adjetivo permite aplicar a um amplo número de pessoas mas se é utilizado como substantivo restringe-se o uso, já que se associa então à uma profissão, a um trabalho formal. Qualquer pessoa que possa fazer conhecer, interessar, impulsionar, sugerir, explicar... é potencialmente um mediador, alcançando muitos ou apenas alguns poucos; que o faça deliberadamente ou espontaneamente. Recomendar a um grupo de amigos ou colegas um romance, falar em um jornal, uma emissora de rádio e uma rede de televisão sobre uma peça de teatro; comentar livros nas redes sociais ou no YouTube; colocar estantes com as novidades na entrada de uma biblioteca ou na vitrine de uma livraria; aconselhar a leitura de algum livro ilustrado para os bebês na consulta do pediatra; explicar um texto poético na sala de aula; ler um livro ilustrado para os filhos antes de dormir... são ações cotidianas de mediação literária. Existem, desse modo, muitos tipos de mediação: privadas e públicas, espontâneas e programadas, desinteressadas e comerciais, pessoais e institucionais. A pluralidade

\footnotetext{
${ }^{2}$ N.E.: A Viagem Maravilhosa de Nils Holgersson, na edição brasileira publicado em 1965 pela Editora Melhoramentos.
}

ANAYA, Juan Mata. Mediação, leitura e literatura. Revista da FUNDARTE. Montenegro, p.01-21, ano 20, № 42, julho/setembro de 2020.

Disponível em: http://.seer.fundarte.rs.gov.br/index.php/RevistadaFundarte/index> 30 de setembro de 2020 


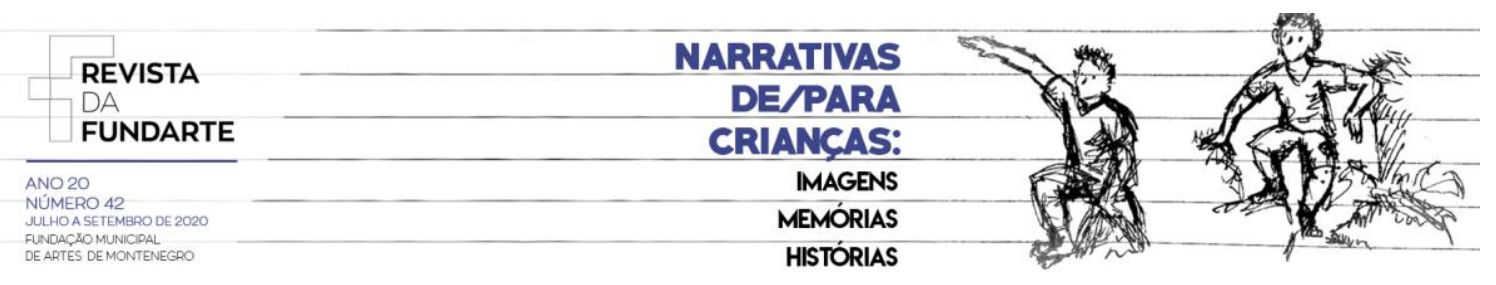

de práticas, cenários e protagonistas demonstram que é necessário evitar a ideia de que a mediação literária é sempre uma atividade homogênea, intencional e sistematizada e que os mediadores respondem a um único perfil. A abrangente definição que faz Munita (2014) acerca do mediador de leitura condensa muito bem suas características:

Um ator que, munido de habilidades e saberes de diversos âmbitos ligados
ao campo cultural e ao trabalho social, intervém intencionalmente com o
propósito de construir condições favoráveis para a apropriação cultural e
participação no mundo da cultura escrita para sujeitos que não tiveram a
possibilidade de desfrutar dessas condições. Ele o realiza fundamentalmente
mediante encontros intersubjetivos, nos quais coloca em jogo seu próprio
mundo interior (afetos, emoções e experiências leitoras) para criar espaço de
acolhida e hospitalidade necessária a toda mediação. (p. 46) (tradução
nossa)

Criar um ambiente acolhedor e respeitoso é, efetivamente, um requisito indispensável em qualquer ação mediadora, pois somente assim é possível superar os obstáculos culturais, psicológicos e sociais que dificultam tantos e tantos cidadãos a estabelecer uma relação fluida e agradável com os textos literários.

A partir da segunda metade do século $X X$, a atenção dispensada à alfabetização como um direito universal teve como consequência a promoção da leitura, que converteu-se em projeto social e educativo de primeira ordem. Nunca na história da humanidade foi tão relevante a presença da cultura escrita e nunca, como hoje, foram tantas as ofertas e possibilidades de acesso à leitura. Buscar ampliar a leitura a um número cada vez maior de cidadãos evidenciou, por sua vez, as limitações e os obstáculos que a dificultam. Não é suficiente que os livros sejam de domínio público e que estejam ao alcance de qualquer pessoa que entre em uma biblioteca, mas também é necessário que a possibilidade teórica de acesso aos livros se converta em uma possibilidade real de acesso. Obstáculos de diferentes naturezas - culturais, econômicos, psicológicos, informativos, emocionais - anulam com frequência essa possibilidade. Entender, assimilar e integrar novas práticas culturais como a leitura, ainda mais se são distantes do mundo familiar e social a que se pertence, necessita compreensão, intenção e tempo. É um processo, não 


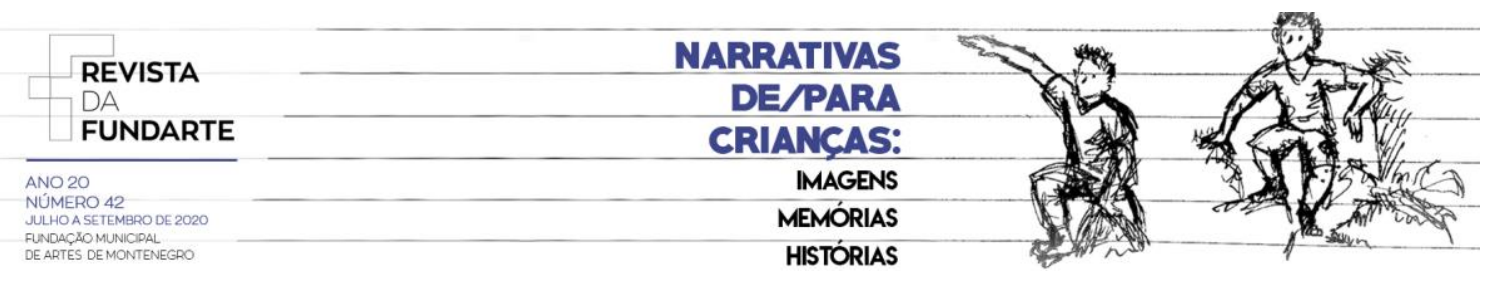

uma mutação mágica. Partindo disso está a importância e a necessidade da mediação. Mediação não só com quem não sabe ler, como historicamente se deu, mas também com aqueles que, sabendo ou podendo ler, não sentem vontade ou não encontram motivos ou sentidos para fazê-lo. Isso requer experiências e mediações. Refletir sobre quem faz a mediação, entre quem ou o que se deve mediar, para que mediar ou porque é necessário mediar é, no fim das contas, um modo de perguntar porque e para que é necessário ler.

\section{Mediação e leitura literária}

A mediação literária não pode ser entendida separadamente de outras mediações culturais e sociais. Faz parte da rede de estratégias encaminhadas a ampliar o número de cidadãos beneficiários dos bens culturais, sejam museus, teatros, auditórios ou parques científicos. As bibliotecas são, nesse sentido, espaços em que se deve desejar ir, para onde se vai se se deseja ler, porque o desejo da leitura é um requisito prévio para o livre desfrute dos livros. A curiosidade das crianças em relação aos livros tem que ser transformada progressivamente em desejo de ler, o que requer complexos processos de mediação, sobretudo em ambientes familiares e sociais nos quais a leitura, incluindo a presença física de livros, não é uma prática arraigada. Compreende-se então que o conceito de mediação literária surgiu acompanhado do conceito de animação de leitura, cujos objetivos básicos eram descobrir, promover, oferecer, alentar, facilitar a leitura (MATA, 2008).

Não obstante, a mediação literária possui características que a distinguem de outros tipos de mediação. Como se disse anteriormente, a mediação no seu sentido mais usual tem como objetivo resolver situações conflituosas ou servir de enlace entre grupos ou pessoas em enfrentamento, mas a mediação literária não busca os mesmos fins. Não é a mesma coisa mediar alunos em conflito por determinado motivo e mediar alunos e livros, ainda que, em ambos os casos, se utilize o mesmo 


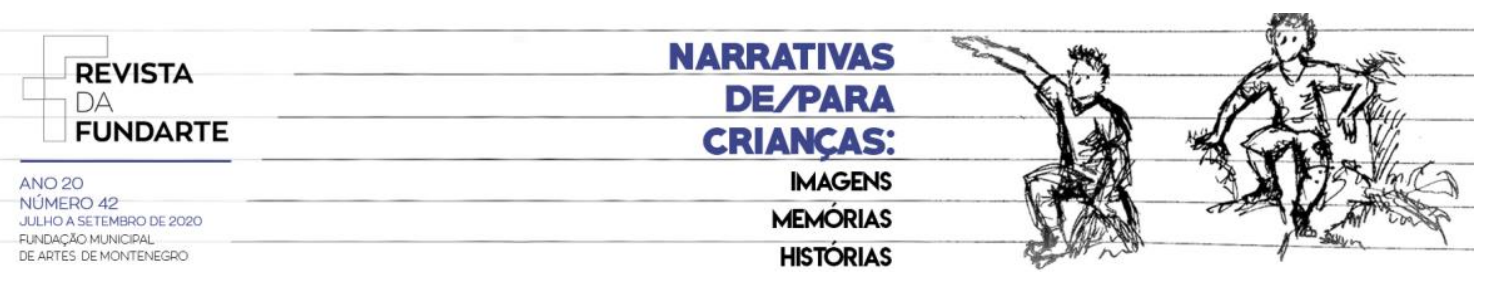

termo. No primeiro caso existe um conflito real; no segundo, não. Mais do que resolver diferenças, a mediação literária tem como finalidade proporcionar conhecimento, despertar interesse, valorizar, despertar desejos, criar hábitos, sobretudo naquelas pessoas, tanto crianças como adultos, cujo entorno social ou familiar não propicie a proximidade e a estima dos livros.

A mediação literária tem como objetivo básico favorecer o conhecimento e a leitura de textos literários. Como se disse anteriormente, a mera presença de livros não garante a leitura. Ler é uma prática cultural cuja conquista requer destreza, tempo, oportunidades e sentido. Existem circunstâncias que a favorecem e outras que a dificultam. Está claro que tornar visível os livros é um requisito fundamental. Não se pode desejar ou apreciar o que não se vê. A mera presença de um livro não assegura o desejo de ler, mas é um convite e uma possibilidade. Sua ausência, por outro lado, é devastadora. Do mesmo modo, a leitura necessita possuir um valor. Ler deve ter um significado para qualquer leitor. Uma pessoa lê com mais motivação e prazer se busca algo nessa leitura. As leituras impostas, obrigatórias, forçadas não geram nem interesse, nem sentido. A satisfação de ler é, portanto, um requisito para seguir lendo. $O$ ato de ler se rege pelos mesmos estímulos que os demais atos humanos: nos aproximamos ao que nos oferece algum tipo de gratificação ou recompensa e nos afastamos do que nos causa dor ou incômodo.

A mediação literária não pode limitar-se a fazer presente os livros diante de possíveis leitores ou leitoras. Esse objetivo é muito pobre. É louvável, mas insuficiente. Se apenas pretendemos levar as crianças ou os adultos a se encontrarem com os livros, a mediação ficaria incompleta. É muito importante desbloquear o caminho dos obstáculos que obstruem esse encontro, é preciso continuar avançando, fortalecendo. Uma mediação não pode limitar-se a acompanhar ou desenhar itinerários. Frequentemente essas mediações afetam aspectos profundos da vida. Petit (1999) destaca a influência determinante que professores e bibliotecários podem ter, por exemplo, em jovens imigrantes ou habitantes de bairros periféricos ou marginalizados. 


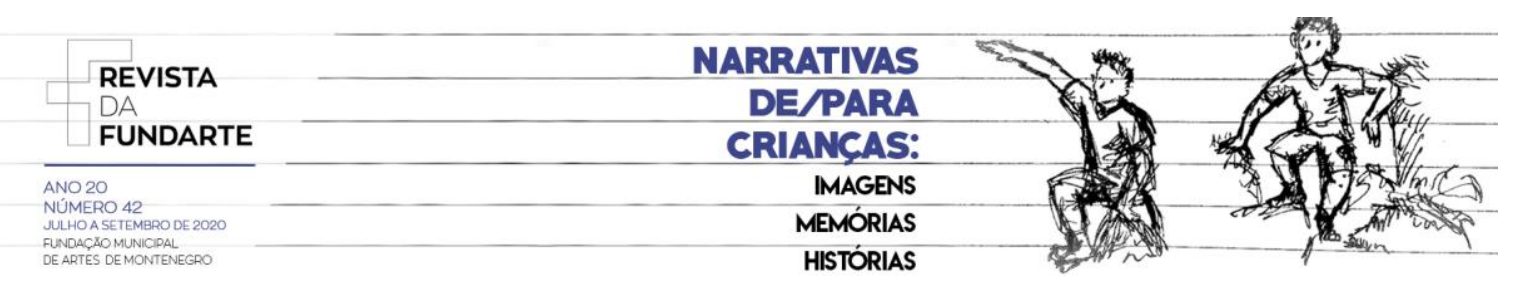

\begin{abstract}
Se compreende que, salvo os casos em que ler é algo "dado", salvo os casos em que se nasceu entre livros, os iniciadores aos livros desempenharam um papel chave. Quando um jovem provém de um meio em que predomina o medo do livro, o mediador pode autorizar, legitimar um desejo mal afirmado de ler ou aprender, inclusive revelá-lo. E outros mediadores poderão acompanhar em seguida o leitor em diferentes momentos do seu percurso ( $p$. 154)(tradução nossa)
\end{abstract}

Embora todo ato de mediação corra o risco de ser um ato de imposição, a autoridade de quem 'sabe' orientando arbitrariamente as ações e as decisões daquele que 'não sabe', a mediação literária pode ter efeitos transformadores que vão além da simples recomendação ou facilitação. Pode servir de abertura a mundos desconhecidos e promissores que dão um novo sentido às pessoas cuja existência está determinada pelo âmbito familiar e social no qual se desenvolvem. Nesse sentido, a mediação literária pode ter uma dimensão cívica e ética.

A mediação literária deve contribuir, deste modo, para a construção de significados. Além da elementar capacidade de dar som às letras e palavras, aprender a ler supõe ativar um conjunto de operações mentais - relacionar, inferir, comparar, deduzir, associar - que, combinadas, dão sentido ao texto que se lê. A isso denominamos 'compreensão'. Compreender não é sinônimo de descobrir, mas de construir. Aprender esse procedimento intelectual e emocional requer tempo, prática e orientação, sobretudo nos momentos iniciais de aprendizagem. Cada novo texto pede uma leitura específica, renovada. Aprender a ler é aprender a construir significados, um processo marcado por mediações. Aprendemos a ler sempre ao lado de alguém: os pais, os professores, os bibliotecários, os colegas, os professores, os amigos... E esse processo se mantém ao longo da vida. A mediação é, portanto, uma maneira de ensinar a interpretar e dar significados aos textos, de descobrir os procedimentos para compreendê-los, ainda mais quando se trata de textos clássicos; quer dizer, textos que carecem de atualidade e do valor do contemporâneo. A mediação literária tem, neste caso, uma tarefa fundamental: desvelar, ressaltar, contextualizar, relacionar, interpretar, a fim de que o passado possa ser compreendido sob a ótica do presente.

ANAYA, Juan Mata. Mediação, leitura e literatura. Revista da FUNDARTE. Montenegro, p.01-21, ano 20, ํㅡ 42, julho/setembro de 2020.

Disponível em: http://.seer.fundarte.rs.gov.br/index.php/RevistadaFundarte/index> 30 de setembro de 2020 


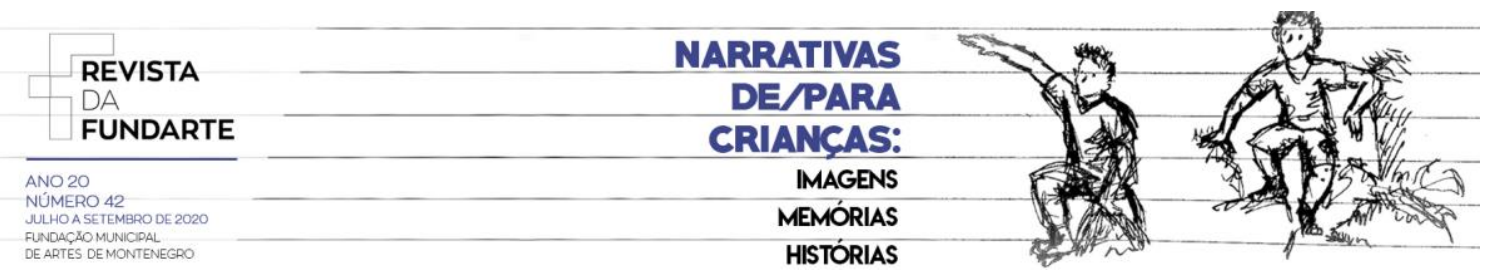

A mediação literária deve ser tanto emocional como intelectual. É um erro subestimar os aspectos afetivos da mediação literária. Parece que o fato de que a mediação literária se produza majoritariamente na sala de aula obriga ao direcionamento para a análise dos textos - estrutura, referências, classificações, inferências, comparações - em detrimento dos aspectos emocionais. Nessa falta de consideração está a origem de muitos fracassos e insatisfações, e desfigura com frequência o trabalho de mediação. As emoções são primordiais em qualquer processo de recepção cultural e a leitura literária não é uma exceção.

A mediação literária deve pretender, portanto, criar experiências de leitura que afirmem e valorizem o desejo de ler, de seguir lendo. Para os bebês, os livros são impressionantes objetos a partir dos quais surgem sons que seus pais emitem com uma voz calma e melodia. E essas primeiras experiências com a leitura são basicamente emocionais. Escutar as palavras que seus pais leem atrai sua atenção, os tranquiliza, faz descobrir sons e palavras, os comove, atiça a imaginação, os estimula... Todas as experiências de leitura deveriam ser reproduções das experiências leitoras da infância. Não há nunca garantia, mas parece razoável pensar que uma sucessão de experiências prazerosas de leitura pode contribuir a fazer com que este ato se torne uma prática duradoura e desejável. Não bastam os discursos, inclusive os bons discursos, em defesa da leitura para criar leitores. Tampouco é suficiente a capacidade de persuasão dos mediadores espontâneos ou profissionais. São necessárias muitas, encadeadas e significativas experiências de leitura para que essa prática se arraigue e se consolide. Larrosa (2003) afirma a respeito:

Para que a leitura ocorra na formação é necessário que haja uma relação íntima entre o texto e a subjetividade. E se poderia pensar essa relação como uma experiência, ainda que entendendo a experiência de um modo particular. A experiência seria o que nos passa. Não o que passa, mas sim o que nos passa (p. 28) (tradução nossa).

ANAYA, Juan Mata. Mediação, leitura e literatura. Revista da FUNDARTE. Montenegro, p.01-21, ano 20, no 42, julho/setembro de 2020.

Disponível em: http://.seer.fundarte.rs.gov.br/index.php/RevistadaFundarte/index> 30 de setembro de 2020 


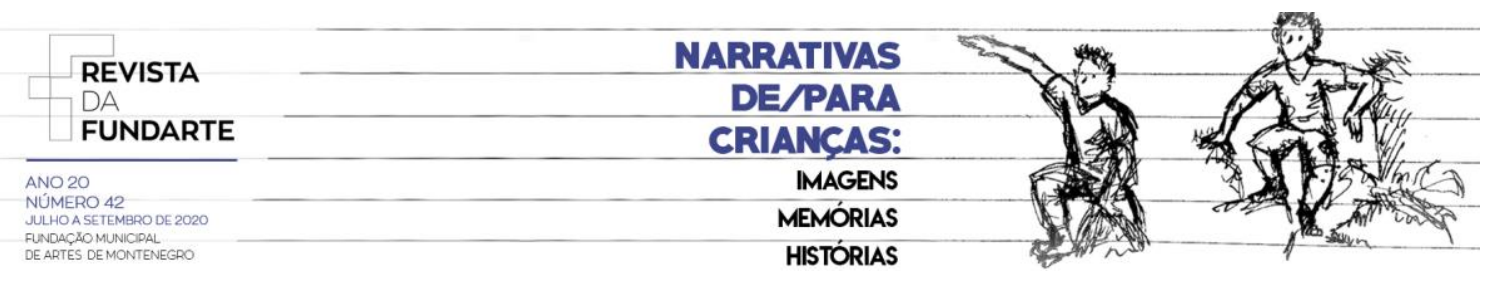

A mediação literária tem como função não só fazer presente os livros ante aos potenciais leitores, mas valorizar a leitura, despertar interesses e expectativas, criar motivação e a necessidade, ajudar a descobrir, dar oportunidade e continuidade à leitura, fazer com que as experiências com os livros sejam significativas e gratificantes. Tudo isso implica, por sua vez, confiança no poder civilizatório e emancipador da leitura e compromisso com as vidas das pessoas a que se destinam os processos de mediação.

\section{Espaços sociais e mediação literária}

Como dito anteriormente, a mediação literária pode ocorrer em qualquer lugar e em qualquer circunstância, assim como ser empreendida pelos mais diversos atores. O lar, como dissemos, é um espaço primordial de mediação (BONNAFÉ, 2008; MATA,2015), assim como pode ser a internet, graças aos novos 'mediadores digitais' (MILÁN, 2011). E é justamente essa diversidade que pode assegurar o êxito das mediações.

A escola é um dos espaços formais de mediação literária. Por sua própria natureza e função, as salas de aula - e também as bibliotecas, os corredores, os pátios, as quadras de esporte, são espaços de mediação. Todo ato educativo é, propriamente falando, um processo mediador, entendido como uma via de relação entre os saberes e os alunos. O ensino trata-se, em essência, de tornar acessíveis e compreensíveis os conhecimentos da humanidade. Essa aprendizagem requer atividades de mediação. Uma sala de aula é uma mediação, uma visita a um museu é uma mediação, uma conferência é uma mediação, uma apresentação teatral é uma mediação... Se aprende também sozinho, através da observação, da leitura, das conversas e da reflexão, mas se avança com maior segurança e maior capacidade de visão se tivermos pessoas que favoreçam esse avanço. A mediação pode ser entendida, desse modo, não apenas como uma prática para resolver 


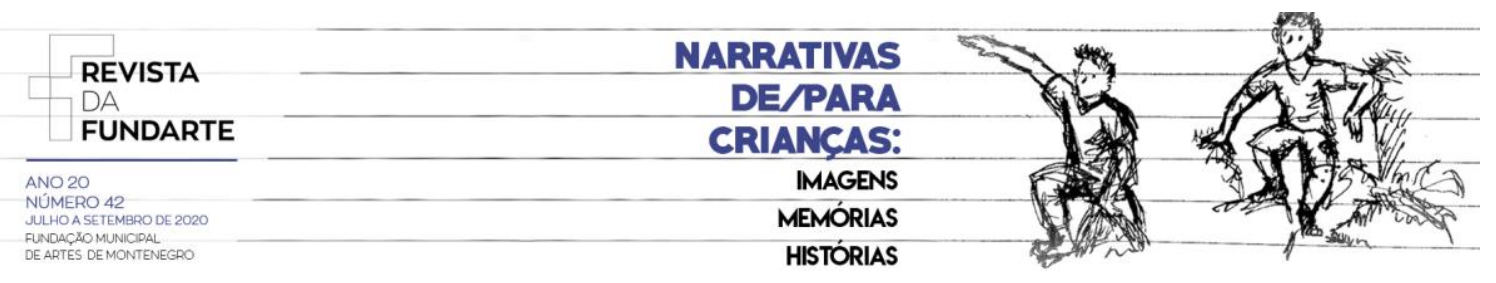

conflitos, mas também para criar ou facilitar vínculos entre objetos ou ideias e pessoas e por sua vez dar sentido essa relação (CARDINET, 2000).

A mediação literária encontra na sala de aula um espaço privilegiado onde manifestar-se. Em primeiro lugar, porque são espaços em que os livros têm uma presença capital, já que não há educação sem textos nem leitura. Em segundo lugar, e talvez mais importante, porque são espaços abertos a todos, que acolhem todas as crianças e adolescentes sem distinção, além daqueles que carecem de estímulos sociais ou familiares para fazer da leitura uma prática habitual e valorosa. E essa circunstância outorga ao espaço escolar um valor excepcional.

O problema é que nem sempre o meio escolar atua como um bom espaço de mediação literária. Poderíamos dizer inclusive que, com frequência, as mediações literárias realizadas na sala de aula se mostram equivocadas, rotineiras e pouco significativas, quando não diretamente dissuasivas. Se confundem com frequência com a distribuição de aulas e o desenvolvimento do currículo, sendo que a primazia concedida ao cumprimento exaustivo dos programas, assim como a prioridade dada à análise estrutural dos textos e à aprendizagem sistemática de nomenclaturas, obras, listas, datas, classificações, etc., faz com que o conhecimento e a leitura dos livros resulte numa tarefa quase impossível.

Com frequência, com a desculpa de ensinar literatura, se buscam na realidade outros objetivos, como ensinar gramática, história literária ou figuras de linguagem. Qualquer prática mediadora na escola deve se perguntar que tipo de relação com os livros pretende promover, pois as finalidades determinam os procedimentos. O importante é o processo. Podem existir bons propósitos, mas práticas mal-sucedidas. Se considerarmos o trabalho docente como uma mediação no sentido estrito, então temos que reconhecer que nem todas as atividades realizadas são coerentes e incentivadoras. Se produz aí uma infeliz contradição: é preciso um lugar específico para essa tarefa de descobrimento e iniciação, mas essa se realiza, com frequência, por meio de procedimentos que a desnaturalizam, a 


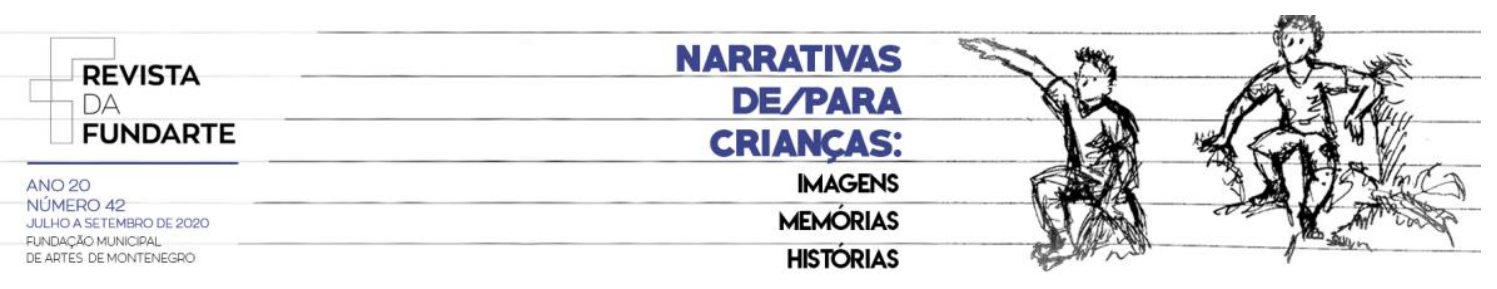

tergiversam ou a anulam. Mais do que mediar, no sentido de facilitar o encontro, o que os adultos fazem é atravessar, quer dizer, dificultando ou esmorecendo.

Esse paradoxo traz inevitavelmente a questão da formação dos mediadores de leitura que estão na escola, cuja carências ou deficiências pedagógicas podem ser um sério obstáculo para alcançar um feliz encontro entre os livros e os possíveis leitores. Se o problema traz inquietação em qualquer âmbito social, é ainda mais preocupante no âmbito escolar. A formação dos futuros professores nesse campo costuma ser limitada e pode ter consequências fatais pois, em decorrência dessa anomalia, o espaço que devia ser o mais propício para mediação literária pode ser o mais dissuasivo. A boa formação inicial e continuada desses mediadores é fundamental se a intenção é resolver essas contradições (CERRILLO; LARRAÑAGA; YUBERO, 2002; COLOMER, 2004; MARTÍN-BARBERO; LLUCH, 2011; LCFL, 2017).

Nesse projeto de mediação, as bibliotecas escolares podem cumprir uma função capital. Diferentemente das salas de aula, nas quais a relação com a literatura está determinada por programas, explicações, cânones, dados e avaliações, as bibliotecas escolares oferecem a possibilidade de leitura mais livre e significativa. As mediações desenvolvidas na biblioteca, incluindo aquelas desenvolvidas pelos mesmos professores que atuam na sala de aula, têm um caráter mais espontâneo, mais prazeroso, mais autônomo, mais desinteressado inclusive, convertendo-as em um espaço fundamental para que se produza o encontro com os livros. Às vezes, a mediação de leitura nas bibliotecas escolares pode se mostrar mais eficaz do que a que se realiza na sala de aula, pois se desenvolve num ambiente mais descontraído, com objetivos mais sociais e críticos e mediante práticas mais abertas e afetivas (CORONAS CABRERO, 2002; DURBAN ROCA, 2010; ÁLVAREZ; CASTRILLÓN, 2011; GARCÍA GUERRERO, 2012).

Poderíamos dizer o mesmo das bibliotecas públicas, espaços abertos e democráticos nos quais o direito e a liberdade de ler se fazem realidade. Por isso mesmo, são espaços nos quais a mediação literária pode alcançar toda a população 


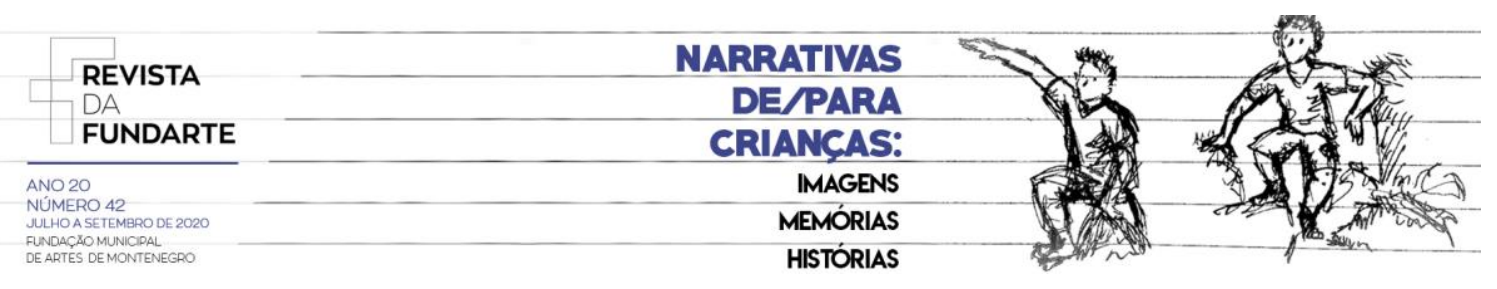

e tornar possível que nenhuma pessoa fique impedida de desfrutar do acervo literário da humanidade. Essa nova consciência permitiu uma renovação do papel dos bibliotecários, agora mais atentos à promoção da leitura e à formação de leitores (CHARTIER; HÉBRARD, 1994). O conceito de 'leitura pública' expressa claramente o desejo de fazer da leitura um mecanismo de emancipação pessoal e social. Nas últimas décadas, as bibliotecas públicas vêm sendo consideradas não só como espaços privilegiados de democratização do conhecimento (ESCOLAR, 1985; PETIT, 1999; MUDDIMAN et al, 2000; BARBIER, 2015) mas como espaços promotores de ações de transformação e integração social. As diretrizes da Internacional Federation of Library Associations para o desenvolvimento de serviços de bibliotecas públicas (IFLA, 2001) incidem na relevante função social das bibliotecas públicas, convertidas cada vez mais em espaços de encontro não só com os livros, mas com outras pessoas, com outras culturas, com outros mundos.

Seu êxito, assim como o da mediação cultural, não depende, todavia, das boas intenções, das boas instalações ou do bom planejamento. Não só é necessário combater a apatia ou o desinteresse, mas também, de modo mais complexo, 0 desconhecimento, os preconceitos e o medo. Essas resistências impedem que o que é destinado a muitos seja patrimônio exclusivo de poucos. É por isso que muitas organizações em todo mundo fazem da mediação literária um modo de intervenção social. É o caso de organizações como People and Stories (www.peapleandstories.org), nos Estados Unidos, Exeko (www.exeko.org), no Canadá, The Reader, no Reino Unido, ou Asociación Entrelibros (www.asociacionentrelibros.es), na Espanha, cujas práticas não se encaminham tanto para animação de leitura no sentido estrito, mas para ressaltar, através dos livros e de sua leitura compartilhada, a dignidade pessoal, a confiança nas próprias aptidões e a emancipação intelectual através da leitura literária. Fazer presente a literatura onde habitualmente ela não está, oferecê-la a pessoas injustamente privadas desse 'capital cultural', para utilizar a expressão de Bourdieu (2000), contribui através da livre expressão intelectual e emocional, ao mútuo intercâmbio de 


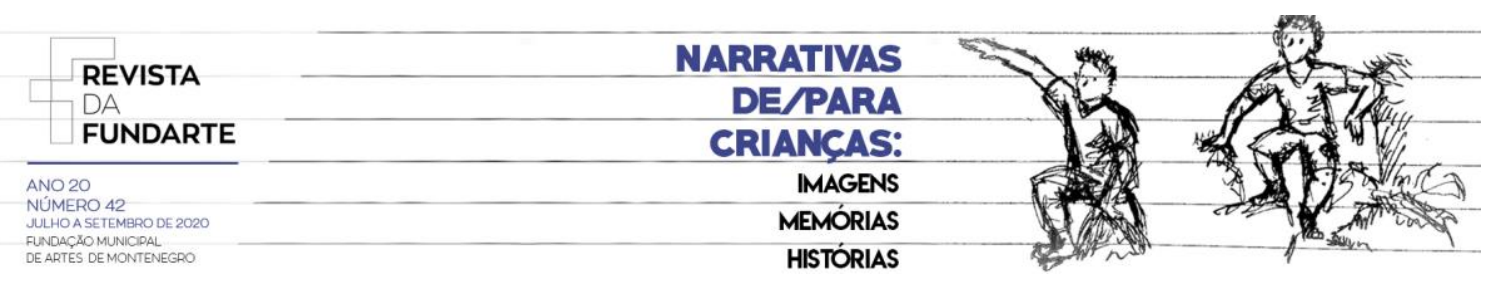

conhecimentos e à participação igualitária em debates e reflexões para adquirir consciência das próprias capacidades e valores pessoais. Substituir uma relação de desinteresse e desconhecimento, ou seja, uma relação negativa ou uma não-relação por uma relação cordial, inclusive vital, com a literatura e com o patrimônio artístico e intelectual em geral, que ganha especial relevância quando levamos em consideração os grupos aos quais habitualmente se dirigem essas iniciativas pessoas encarceradas, mulheres vítimas de violência de gênero, pessoas em situação de rua, pessoas com transtornos mentais, crianças e adolescentes em situação de vulnerabilidade social -, o que propicia que a mediação literária cumpra funções de alívio, consolo, estímulo, bem-estar físico e mental, entusiasmo, esperança e ao mesmo tempo, atue como instrumento de transformação social (CHOVANCOVA, 2018).

Importante destacar que, nesses casos, a mediação literária põe o foco não no patrimônio literário em si, mas nas pessoas e em suas circunstâncias de vida. Em última instância, abrir caminhos entre as pessoas e a literatura objetiva facilitar o acesso à palavra em geral, que permite a comunicação e a participação na sociedade letrada, e à palavra poética em particular, que amplia as capacidades individuais de simbolização. A mediação de leitura ou literária se torna-se "uma prática de intervenção profundamente comprometida e sempre direcionada a impulsionar a vida social em três esferas críticas: a pessoal, a subjetiva social e a cidadã" (ÁLVAREZ; CASTRILLÓN, 2011). Neste sentido, a relação com o patrimônio literário e intelectual não é a única que forja a mediação literária. Graças aos diálogos promovidos pela literatura, se forjam também as relações consigo mesmo, com outras pessoas e com o mundo ao redor.

\section{Referencias:}

ÁLVAREZ, D.; CASTRILLÓN, S. De la mediación de la lectura o de cómo "ir más allá". In: MIRET, I. ; ARMENDANO, C. (Org.): Lectura y bibliotecas escolares. p. 8392. Madrid: OEI-Fundación Santillana, 2011. 


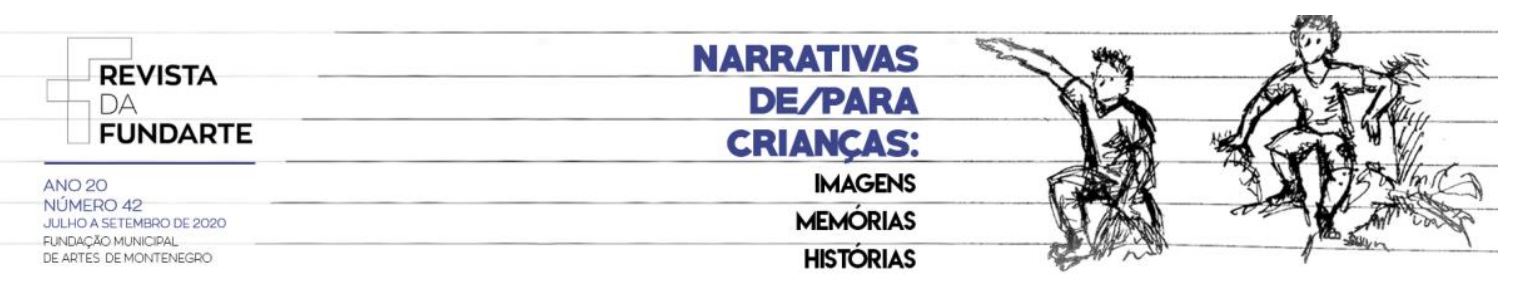

ANDREWS, M. Charles Dickens and his performing selves Dickens and the public readings. Oxford: Oxford University Press, 2006.

BARBIER, F. Historia de las bibliotecas: de Alejandría a las bibliotecas virtuales. Buenos Aires: Ampersand, 2015.

BLANCO GARCíA, M. I. Tratado de mediación. Valencia: Tirant lo Blanch, 2017. BONNAFÉ-SCHMITT, J-P. La médiation, une justice douce. Paris: SyrosAlternatives, 1992.

BONNAFÉ, M. Los libros, eso es bueno para los bebés. Barcelona. Océano, 2008. BOURDIEU, P. Poder, Derecho y Clases Sociales. Bilbao: Desclée De Brouwer, 2000.

BRYANT, P.; BRADLEY, L. Problemas infantiles de lectura. Madrid: Alianza, 1998. CABREJO-PARRA, E. (2001). La lecture avant les textes écrits. A.C.C.E.S. Les Cahiers, 5, p. 19-24, 2001.

CARDINET, A. École et mediations. Toulouse: Editions érès, 2000.

CAVALlO, G.; CHARTIER, R. (org.) Historia de la lectura en el mundo occidental. Madrid: Taurus, 1998.

CERRILLO, P. C.; LARRAÑAGA, E.; YUBERO, S. Libros, lectores y mediadores. Cuenca: Ediciones de la Universidad de Castilla y La Mancha, 2002.

CHARTIER, A. M.; HÉBRARD, J. Discursos sobre la lectura (1880-1980). Barcelona: Gedisa, 1994.

CHOVANCOVA, L. Literatura, lectura y diversidad. Tesis doctoral, Universidad de Granada, 2018.

COLOMER, T. El papel de la mediación en la formación de lectores. In: COLOMER, T.; FERREIRO, E.; GARRIDO, F.: Lecturas sobre lecturas. México D. F.-Bogotá: Consejo Nacional para la Cultura y las Artes/Asociación colombiana de lectura y escritura, Asolectura, 2004.

CORONAS CABRERO, M. La Biblioteca Escolar. Una aventura alfabética.I Jornadas de Bibliotecas Escolares de Asturias. p. 101-111. Llanes: Centro del Profesorado y de Recursos de Oriente, 2002.

DURBAN ROCA, G. La biblioteca escolar, hoy. Barcelona: Graó, 2010. 


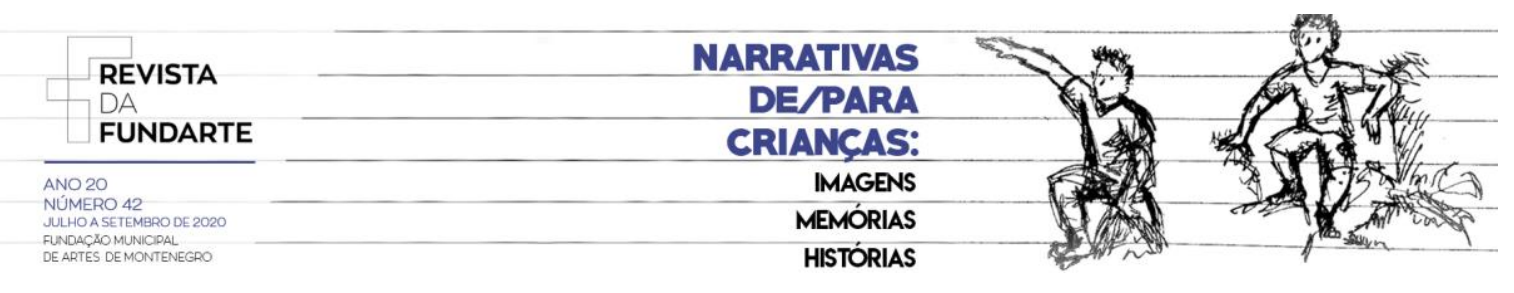

ESCOLAR, H. Historia de las bibliotecas. Madrid: Fundación Germán Sánchez Ruipérez, 1985.

GARCÍA GUERRERO, J. Contribución de la biblioteca escolar al fomento de la lectura. Sevilla: Junta de Andalucía, Dirección General de Ordenación y Evaluación Educativa, 2012.

GROVER DUFFY, K.; GROSCH, J. W.; OLCZAK, P. V. La mediación y sus contextos de aplicación. Una introducción para profesionales e investigadores. Barcelona: Paidós, 1996.

IFLA/UNESCO. Directrices para el desarrollo del servicio de bibliotecas públicas. (Disponível em https://unesdoc.unesco.org/ark:/48223/pf0000124654 spa (consulta 10 de mar de 2019)

Larrosa, J. La experiencia de la lectura. Estudios sobre literatura y formación. México D.F.: Fondo de Cultura Económica, 2003.

LCFL. Laboratorio Contemporáneo de Fomento de la Lectura. Nuevas destrezas para los mediadores de la lectura. (Disponível em: https://fundaciongsr.org/lasnuevas-destrezas-para-mediadores-de-lectura). Consulta 3 de mar de 2019.

MANGUEL, A. Una historia de la lectura. Madrid: Alianza, 1998.

MARQUES CEBOLA, C. La mediación. Madrid: Marcial Pons, 2013.

MARTín-BARBERO, J.; LLUCH, G. Proyecto: Lectura, escritura y desarrollo en la sociedad de la información. Bogotá: Cerlalc-Unesco, 2011.

MATA, J. El rastro de la voz y otras celebraciones de la lectura. Granada: Universidad de Granada, 2014.

MATA, J. 10 Ideas Clave Animación a la lectura. Barcelona: Graó, 2008.

MATA, J. Casas lectoras. Madrid: Lectyo. Fundación Germán Sánchez Ruipérez, 2015.

MENÉNDEZ PIDAL, R. Poesía juglaresca y juglares. Madrid: Espasa-Calpe, 1942.

MILLÁN, J. A. El lector en red. In: MIRET, I.; ARMENDANO, C. (org.): Lectura y bibliotecas escolares. p. 49-56. Madrid: OEI-Fundación Santillana, 2011. 


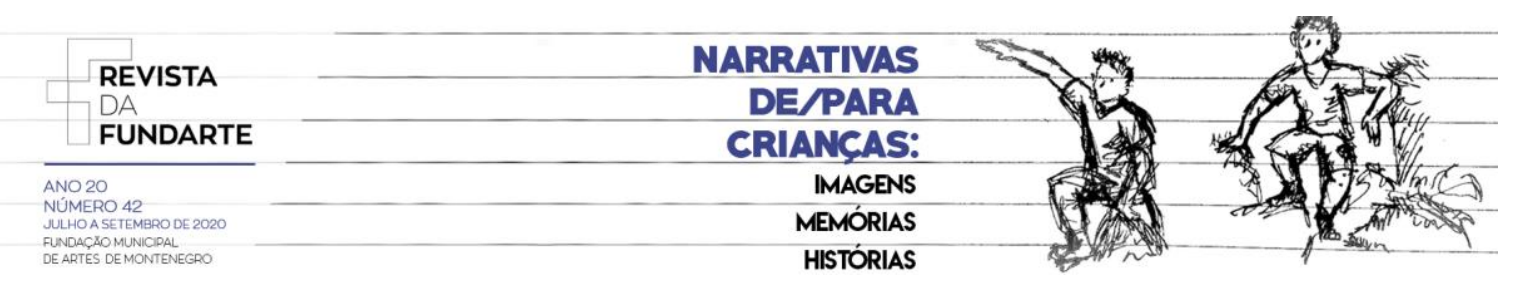

MUDDIMAN, D. et al. Open to All? The public library and social exclusion: executive summary. London: The Council for Museums, Archives and Libraries. Library and Information Commission, 2000.

MUNITA, F. El mediador escolar de lectura literaria. Un estudio del espacio de encuentro entre prácticas didácticas, sistemas de creencias y trayectorias personales de lectura. Tesis doctoral, Universitat Autònoma de Barcelona, 2014.

MUNNÉ, M.; MAC-CRAGH, P. Los 10 principios de la cultura de mediación. Barcelona: Graó, 2006.

PETIT, M. Nuevos acercamientos a los jóvenes y la lectura. México D.F.: Fondo de Cultura Económica, 1999.

PETIT, M. El arte de la lectura en tiempos de crisis. Barcelona: Océano, 2009.

PÖCHHACKER, F. Interpreting as mediation, In: VALERO-GARCÉS, C.; MARTIN, A. (org.) Crossing Borders in Community Interpreting: Definitions and dilemmas. Amsterdam: John Benjamins Publishing Company, 2008.

POPPER, K. Búsqueda sin término. Una autobiografía intelectual. Madrid: Tecnos, 1994.

SIX, J. F. Dinámica de la mediación. Barcelona: Paidós, 1997.

SOUTO GALVÁN, E. La mediación: un instrumento de conciliación. Madrid: Dykinson, 2010.

VALERO-GARCÉS, C. Mediation as translation or translation as mediation?.

(Disponível em

https://www.researchgate.net/publication/266005612 Mediation as translation or translation as me diation Widening the translator\% $27 \mathrm{~s}$ role in a new multicultural society. Consulta $28 \mathrm{de}$ feb de 2019)

VIAGGIO, S. Teoría general de la mediación interlingüe. Alicante: Universidad de Alicante, 2004.

VINYAMATA CAMP, E. Aprender mediación. Barcelona: Paidós, 2003.

WELLS, G. Aprender a leer y escribir. Barcelona: Laia, 1988.

WOLF, M. Cómo aprendemos a leer. Historia y ciencia del cerebro y la lectura. Barcelona: Ediciones B, 2008. 